\title{
Serum Amyloid A (SAA3) Produced by Rabbit Synovial Fibroblasts Treated with Phorbol Esters or Interleukin 1 Induces Synthesis of Collagenase and Is Neutralized with Specific Antiserum
}

\author{
Teresa I. Mitchell," Charles I. Coon, ${ }^{*}$ and Constance E. Brinckerhoff** \\ Departments of ${ }^{*}$ Medicine and ${ }^{\ddagger}$ Biochemistry, Dartmouth Medical School, Hanover, New Hampshire 03756
}

\begin{abstract}
We report that nucleic acid sequence analysis of a full-length cDNA clone for a rabbit serum amyloid $A$ (SAA)-like protein has identified this protein as more closely related to SAA3 than to SAA1. SAA3 induced collagenase synthesis in rabbit synovial fibroblasts, and immune IgG raised against this SAA protein abrogated the induction. Using antisera to immunoprecipitate biosynthetically labeled ${ }^{3} \mathrm{H}-\mathrm{SAA}$ and ${ }^{3} \mathrm{H}$-collagenase from culture medium, we compared the levels of SAA and collagenase synthesized by cultures of rabbit fibroblasts at early passage (passages 3-6) with those synthesized by late passage cells (passage 16). Comparatively high levels of both proteins were produced constitutively by fibroblasts at low passage. With increasing passage, levels of both proteins drop so that by passage 16, constitutive production of SAA and collagenase was only $\sim 15-20 \%$ that of passage 3 cells. Cells at low passage could be readily stimulated with phorbol myristate acetate (PMA) or interleukin 1 (IL-1) to synthesize increased amounts of both SAA and collagenase. In passage 5 cells treated with PMA, we detected increased SAA mRNA by $1.5 \mathrm{~h}$ and collagenase mRNA by 5 h. However, older passage cells were more refractory to stimulation and required longer induction times. We suggest that SAA3 may be expressed by fibroblasts at sites of acute inflammation or injury, and that elevated levels of SAA3 may signify "activated" fibroblasts which are already producing increased amounts of collagenase constitutively and which are predisposed to further stimulation. (J. Clin. Invest. 1991 . 87:1177-1185.) Key words: metalloproteinase • gene expression • inflammation • rheumatoid arthritis • SAA
\end{abstract}

\section{Introduction}

The serum amyloid A (SAA) $)^{1}$ proteins, of $\sim 14 \mathrm{kD}$ (reviewed in 1,2$)$ are precursors to the amyloid $A(A A)$ protein, a major constituent of the fibrous deposits in amyloidosis associated with chronic inflammatory disorders, such as rheumatoid arthritis and ankylosing spondylitis (3). SAA is an acute phase reactant, synthesized principally by the liver in response to stress or inflammation, and it is secreted and transported in the plasma complexed with high density lipoprotein $(1,2)$. Its function is unknown.

Received for publication 22 August 1990 and in revised form 14 November 1990

1. Abbreviation used in this paper: SAA, serum amyloid A.

J. Clin. Invest.

(c) The American Society for Clinical Investigation, Inc.

$0021-9738 / 91 / 04 / 1177 / 09 \$ 2.00$

Volume 87, April 1991, 1177-1185
In the mouse, SAA1 and SAA2 are similar genes encoding proteins which differ from each other at only nine of 103 amino acid positions (4). These genes are $95 \%$ homologous in both coding and noncoding regions. A third gene, SAA3, is only $70 \%$ homologous with SAA1. In the human, two forms of amyloid protein, SAA1 and SAA2, are present in serum, with SAA 1 being predominant $(1,2,5-8)$. A third form has recently been described and although it was designated GSAA1 (9), it appears to share more homology with mouse SAA3 than with SAA1 (4).

Recently, we isolated an autocrine protein produced by rabbit fibroblasts that induced the synthesis of collagenase in these cells (10). Collagenase is the only enzyme active at neutral $\mathrm{pH}$ that can initiate breakdown of the interstitial collagens, I, II, and III, thus assigning it a major role in the normal modeling and remodeling of the extracellular matrix (wound healing, uterine resorption) and in the destruction of connective tissue in diseases states (rheumatoid and osteoarthritis, and tumor invasion) (reviewed in 11). Amino acid sequencing of the 25 $\mathrm{NH}_{2}$-terminal residues of this autocrine protein identified it as an SAA-like protein, $M_{\mathrm{r}} 14 \mathrm{~K}$ (10).

In this paper, we continue our characterization of rabbit fibroblast SAA as we begin to understand how this protein induces collagenase synthesis. To this end, we have developed a polyclonal antiserum to rabbit fibroblast SAA and showed that this antiserum can neutralize the ability of SAA to induce collagenase. We have isolated a cDNA clone and found that this cDNA has greater homology to human and mouse SAA3 than to SAA1. Finally, we have studied the relationship between SAA and collagenase synthesis in cells following the addition of two inflammatory mediators, phorbol myristate acetate (PMA) or IL-1. We conclude that increased synthesis of SAA3 may be a step in a pathway leading to increased collagenase synthesis.

\section{Methods}

Cell culture. Rabbit synovial fibroblasts were derived from the knee synovium of 5-wk-old New Zealand White rabbits (Millbrook Farms, Amherst, MA) by digestion with bacterial collagenase $(4 \mathrm{mg} / \mathrm{ml}$; Worthington Cooper Biomedical, Freehold, NJ) $(10,12)$. Monolayers of primary cultures were grown to confluence in DMEM with $20 \%$ FCS (Gibco, Grand Island, NY) with penicillin and streptomycin (Gibco). At confluence, cells were passaged 1:2 with $0.25 \%$ trypsin (Gibco) in $10 \%$ FCS. For experiments, cells were washed three times in HBSS ( 5 $\mathrm{min} /$ wash) to remove traces of serum and then placed in serum-free DMEM supplemented with $0.2 \%$ lactalbumin hydrolysate (LH). Unless noted otherwise, experiments were performed with cells between passage 4 and 7.

Purification of SAA protein, preparation of polyclonal antiserum, and isolation of $I g G$. SAA protein was purified from conditioned medium as described previously $(10,12)$. Briefly, rabbit synovial fibroblasts were cultured in DMEM-LH with PMA $\left(10^{-8} \mathrm{M}\right)$ for $48 \mathrm{~h}$. Con- 
ditioned medium was harvested and SAA was isolated by isoelectric focusing with a Rotofor apparatus (Bio-Rad Laboratories, Inc., Richmond, CA), and material focusing at pI 5 or 8 was applied to a Beckman TSK HPLC gel filtration column in $20 \mathrm{mM}$ phosphate buffer, $0.15 \mathrm{M} \mathrm{NaCl}, \mathrm{pH}$ 7.5. SAA eluted in fractions corresponding to $M_{\text {r }}$ $<15 \mathrm{~K}$. In some experiments, SAA was further purified by SDS-PAGE and elution of the protein band from the SDS gel.

For preparation of antiserum, purified SAA to be used as antigen was isolated by SDS-PAGE and eluted from the gel. It was passed over an AG 11 A8 ion retardation resin column (Bio-Rad Laboratories, Inc.) to remove SDS (10) and then dialyzed so that it would at least partially renature before being injected into a sheep. Before immunization, a preimmune bleed was taken. For each injection, $\sim 20 \mu \mathrm{g}$ of gel-purified SAA protein was mixed with complete Freund's adjuvant and injected subcutaneously into the sheep. At 2-wk intervals, the sheep was bled and booster injections were given for a total of five injections. Serum was stored at $-20^{\circ} \mathrm{C}$. IgG was isolated from both preimmune and immune sera by an Immunopure Immobilized Protein G column (Pierce Chemical Co., Rockford, IL) according to the manufacturer's protocol.

Western blot analysis and immunoprecipitation. For Western blots, crude culture medium taken from PMA-stimulated rabbit fibroblasts was partially purified by isoelectric focusing. $10 \mu \mathrm{g}$ protein was applied to each lane of a 7-15\% SDS polyacrylamide gradient gel and electroblotted onto PVDF membrane (Immobilon; Millipore Corp., Freehold, NJ). After transfer, selected lanes were stained with Coomassie brilliant blue to visualize total proteins. The remaining portion of the blot was blocked for $1 \mathrm{~h}$ with 10\% FCS in Tween 20 in Tris-buffered saline (TTBS; $0.05 \%$ Tween 20; $50 \mathrm{mM}$ Tris, pH 7.5; $150 \mathrm{mM} \mathrm{NaCl}$ ).
The blot was then treated with preimmune or immune serum, appropriately diluted in TTBS, for $18 \mathrm{~h}$ at room temperature. Immunoreactivity was developed with the Vectastain ABC kit (Vector Laboratories, Burlingame, $\mathrm{CA}$ ): blots were placed in a solution of biotinylated second antibody (rabbit anti-sheep immunoglobulin antiserum, $5 \mu \mathrm{g} / \mathrm{ml}$ in TTBS) for $30 \mathrm{~min}$, washed three times in TTBS, and transferred to the Vectastain $A B C$ reagent (avidin and biotinylated horse radish peroxidase substrate, 4-chloro-1-napthol with imidazole: $2 \mathrm{ml}$ of a $3 \mathrm{mg} / \mathrm{ml}$ solution in methanol added to $10 \mathrm{ml}$ of TTBS, with $50 \mu 12 \mathrm{M}$ imidazole), and $5, \mu \mathrm{l}$ of $30 \% \mathrm{H}_{2} \mathrm{O}_{2}$. Color appeared in 3-15 min.

Immunoprecipitation of ${ }^{3} \mathrm{H}$-SAA and ${ }^{3} \mathrm{H}$-collagenase was performed as we have described previously $(10,12)$. Cells were cultured in medium containing $25 \mu \mathrm{Ci} / \mathrm{ml}\left[{ }^{3} \mathrm{H}\right]$-leucine $(143 \mathrm{Ci} / \mathrm{mmol}$; Amersham Corp., Chicago, IL) for $30 \mathrm{~h}$, and an aliquot (e.g., $500 \mu \mathrm{l}$ ) of medium was added to a cocktail containing $0.5 \mathrm{M}$ arginine hydrochloride, $\mathrm{pH}$ 8.0; $50 \mathrm{mM}$ Tris/HCl buffer, $\mathrm{pH} 8.6 ; 5$ mM EDTA; $1 \%$ (vol/vol) Triton $\mathrm{X}-100$, along with $20 \mu \mathrm{l}$ antiserum. After overnight incubation at room temperature, immune complexes were isolated by addition of protein A Sepharose beads (Sigma Chemical Co., St. Louis, MO). After washing (four times in $0.1 \mathrm{M} \mathrm{Tris} / \mathrm{HCl}, \mathrm{pH} 8.6$, containing $250 \mathrm{mM}$ arginine followed by one water wash), the antigen-antibody complexes were dissociated by boiling in SDS-PAGE sample buffer and were loaded onto a $7.5 \%$ polyacrylamide gel for collagenase and either a 12,15 , or a 7.5-15\% gradient gel for SAA. Immunoprecipitated SAA and procollagenase were visualized by fluorography and were quantitated by excising and counting the protein bands. Radioactivity was extracted from the gel by rehydrating appropriate slices of the gel in $0.5 \mathrm{ml} \mathrm{H}_{2} \mathrm{O}$ for 30 min. $1 \mathrm{ml}$ Solvable (Dupont Co., Wilmington, DE) was then added and the samples were incubated at $50^{\circ} \mathrm{C}$ for $3 \mathrm{~h}$, followed by addition of 20

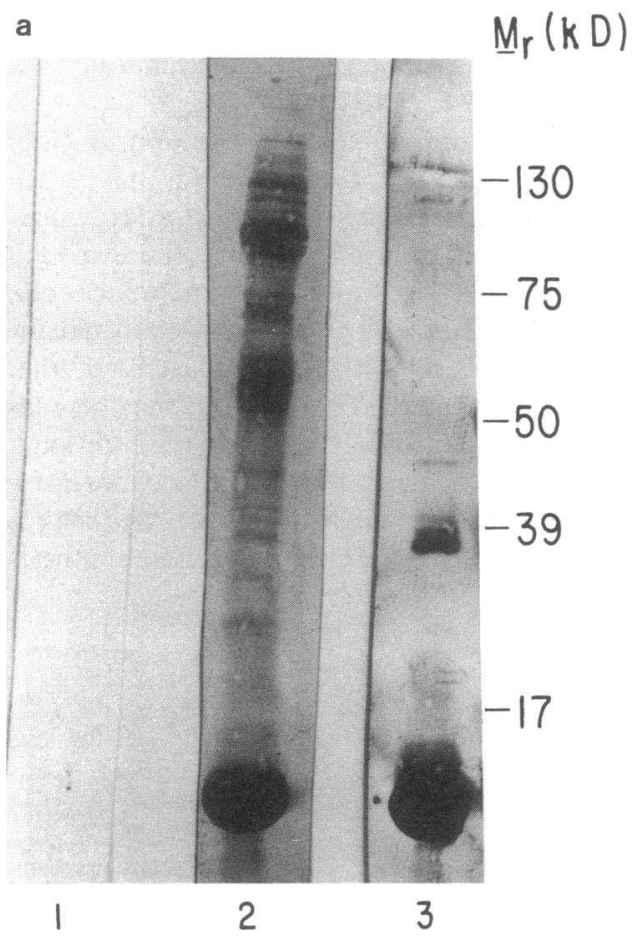

b $\quad$ I 8

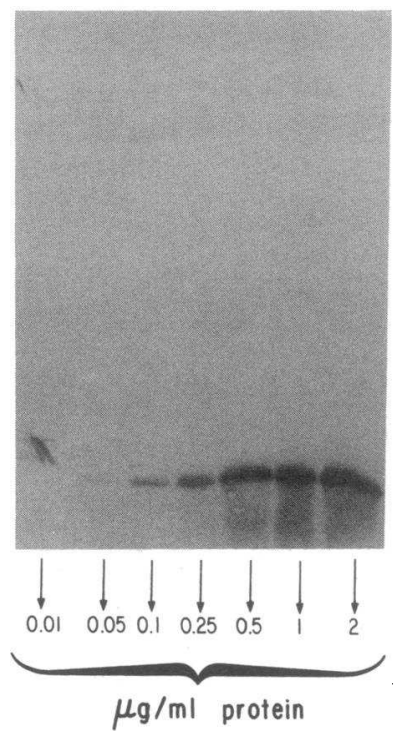

PI 5

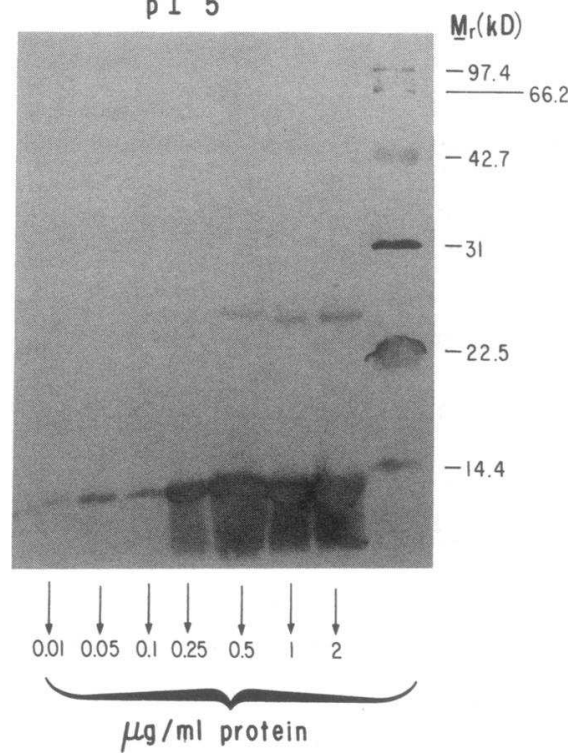

Figure 1. Western blot analysis of rabbit SAA protein. SAA in crude culture medium taken from PMA-stimulated rabbit fibroblasts was partially purified by isoelectric focusing. After transfer to Immobilon, lanes were stained with Coomassie brilliant blue or reacted with preimmune or immune serum. Blots were developed by addition of a biotinylated rabbit anti-sheep immunoglobulin antiserum, avidin, and biotinylated horse radish peroxidase. Immunoreactive proteins were visualized by addition of peroxidase substrate (4-chloro-1-naphthol with imidazole and $\mathrm{H}_{2} \mathrm{O}_{2}$ in $0.1 \mathrm{M} \mathrm{Tris} / \mathrm{NaCl}$ ). The Western blotting protocol and reagents were provided by Vectastain ABC Kit, Vector Laboratories, Burlingame, CA. (a) Preimmune vs. immune serum in which $10 \mu \mathrm{g}$ protein focusing at pI 8 was applied to each lane of a $15 \%$ SDS polyacrylamide gel. (Lane 1 ) Preimmune bleed, 1:5,000. (Lane 2) Total protein, stained with Coomassie brilliant blue. (Lane 3) Immune bleed No. 4, 1:5,000. (b) Dose/response curve of purified rabbit SAA protein vs. immune serum in which varying amounts of SAA were loaded onto a $12 \%$ polyacrylamide gel, and after transfer, reacted with immune bleed 6 at 1:10,000. 
$\mathrm{ml}$ Atomlight (Dupont Co.). After being vortexed and allowed to stand overnight at room temperature, samples were counted in a liquid scintillation spectrometer.

Total cellular protein in the monolayer was determined after removal of the ${ }^{3} \mathrm{H}$-leucine-labeled culture medium. The wells were washed twice with cold $5 \%$ trichloroacetic acid and the monolayer was solubilized in $1 \mathrm{ml}$ of $0.1 \mathrm{~N} \mathrm{NaOH}$. Protein was quantitated with the Bradford reagent (Bio-Rad Laboratories, Inc.). The protein content of a 35-mm-diam culture ranged typically from 90 to $120 \mu \mathrm{g}$ and was not affected by the experimental conditions (10).

Isolation and sequencing of SAA cDNA clones. $\sim 10^{5}$ plaques of a cDNA library in lambda gt 11 prepared from mRNA derived from PMA-stimulated rabbit synovial fibroblasts (13) were screened with a cDNA for human serum SAA 2 (6), labeled with [alpha ${ }^{32}$ ] P (3,000 $\mathrm{Ci} / \mathrm{mmol}$; Amersham Corp.) by the oligolabeling technique (14). Six positive clones were purified through three rounds of plaque purification and were subcloned into the Bluescript plasmid for di-deoxysequencing with the aid of a "helper phage" (Stratagene, Inc., San Diego, CA) to produce single-stranded DNA (15).

Preparation of $m R N A$ and Northern blot analysis. RNA was harvested from confluent cultures of rabbit synovial fibroblasts in 150$\mathrm{mm}$-diameter culture dishes using the guanidine $\mathrm{HCl}$ /cesium chloride method (16). $10-20 \mu \mathrm{g}$ of total RNA was electrophoresed at $4^{\circ} \mathrm{C}$ in a $1 \%$ agarose gel containing $2.2 \mathrm{M}$ formaldehyde, and then transferred to Gene Screen Plus (New England Nuclear/Dupont, Boston, MA). Blots were probed with [alpha ${ }^{32}[\mathrm{P}]-\mathrm{cDNAs}$ for rabbit SAA or collagenase (17), the human $c$-jun cDNA (a gift from Dr. Michael Karin), labeled to specific activities of $0.83 \times 10^{7} \mathrm{cpm} / \mu \mathrm{g}, 1.5 \times 10^{7} \mathrm{cpm} / \mu \mathrm{g}$ and 0.93 $\times 10^{7} \mathrm{cpm} / \mu \mathrm{g}$, respectively, or with a probe for mouse ribosomal RNA (18), a house-keeping gene used to control for variations in loading. Between hybridizations, blots were stripped by boiling for $10 \mathrm{~min}$ in $0.1 \times$ SSC with $1 \%$ SDS. After cooling, the solution was replaced and the blots were again boiled.

\section{Results}

Preparation of polyclonal antiserum vs. rabbit SAA protein. Antiserum to rabbit SAA was characterized by Western blot analysis and by immunoprecipitation of biosynthetically labeled ${ }^{3} \mathrm{H}$ SAA (Figs. 1 and 2). Western blot analysis with partially purified SAA protein revealed that only immune serum but not preimmune serum reacted with SAA protein (Fig. $1 a$ ). The higher $M_{\mathrm{r}}$ band, not prominent in the lane showing a Coomassie blue stain of total proteins, may be an aggregate of the partially purified SAA because we do not see it in crude culture medium (data not shown). Fig. $1 b$ shows that the serum, diluted 1:10,000, detected as little as $10 \mathrm{ng}$ of SAA antigen, and Fig. 2 demonstrates that antiserum dilutions of up to 1:500 immunoprecipitated biosynthetically labeled ${ }^{3} \mathrm{H}-\mathrm{SAA}$ protein from crude culture medium, but that the preimmune serum did not.

Neutralization of SAA induction of collagenase by immune $\operatorname{Ig} G$. To determine whether antibodies to SAA could neutralize collagenase-inducing activity, we isolated IgG from nonimmune and immune serum. This was then mixed with SAA protein, and after $2 \mathrm{~h}$ at $37^{\circ} \mathrm{C}$, the mix was centrifuged and the supernatant was tested for its ability to induce collagenase. Fig. $3 a$ shows that immune $\mathrm{IgG}$ at $1 \mathrm{mg} / \mathrm{ml}$ (bleed 8 ), but not nonimmune IgG (bleed 1), partially neutralized the ability of SAA to induce collagenase synthesis, and Fig. $3 b$ demonstrates that this abrogation of collagenase induction depended on the concentration of immune IgG.

Isolation and sequence analysis of a cDNA clone for rabbit $S A A$. Using a cDNA probe for human SAA2 (6) to screen a

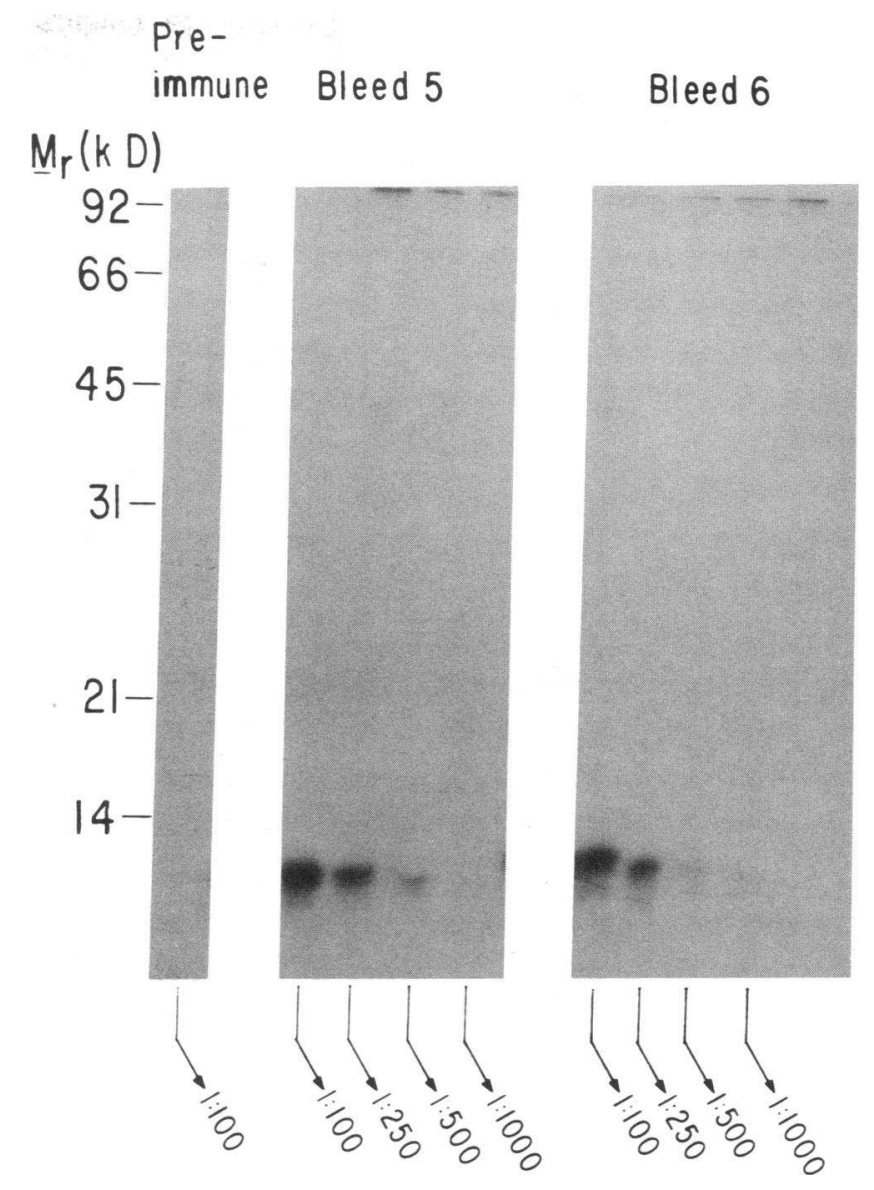

Figure 2. Immunoprecipitation of ${ }^{3} \mathrm{H}-\mathrm{SAA}$ rabbit protein from crude culture medium. Monolayer cultures of rabbit synovial fibroblasts were grown to confluence in 100-mm-diam culture dishes. The cells were then washed and transferred to $10 \mathrm{ml}$ leucine-free medium containing PMA $\left(10^{-8} \mathrm{M}\right)$ and ${ }^{3} \mathrm{H}$-leucine $(25 \mu \mathrm{Ci} / \mathrm{ml})$. After $30 \mathrm{~h}$ incubation, aliquot portions of $750 \mu \mathrm{l}$ culture medium were reacted with preimmune or immune serum. Immunoprecipitated protein was visualized with a $15 \%$ polyacrylamide gel and fluorography. (Lane 1) Preimmune serum diluted 1:100. (Lanes 2-5) Immune serum bleed No. 5 diluted 1:100, 1:250, 1:500, 1:1,000, respectively. (Lanes 6-9) Immune serum bleed No. 6 diluted 1:100, 1:250, 1:500, 1:1,000, respectively.

cDNA library prepared from mRNA taken from phorbolstimulated rabbit synovial fibroblasts (13), we isolated and sequenced six overlapping clones. Nucleic acid sequence analysis of one full-length clone of 471 nucleotides revealed $\sim 78 \%$ homology in the protein coding region with human SAA1 and $\sim 84 \%$ homology with human SAA3 $(6,9)$ (Fig. $4 a$ ). The cDNA encoded a protein of 122 amino acids, $M_{\mathrm{r}} 13,791$, with a deduced sequence that agrees almost completely with that obtained by $\mathrm{NH}_{2}$-terminal sequencing of the purified rabbit protein (10). There are only two exceptions: a serine at position 1 of the secreted native protein vs. arginine at this position in the deduced sequence, and a putative cysteine at position 18 in the native protein vs. a tryptophan in the cDNA. The open reading frame in the cDNA is preceded by a $5^{\prime}$ untranslated region of 44 nucleotides and is followed by a $3^{\prime}$ untranslated region of 58 nucleotides.

Despite the high degree of overall conservation of our rabbit cDNA with both human SAA 1 (5) and SAA3 (9), the homol- 

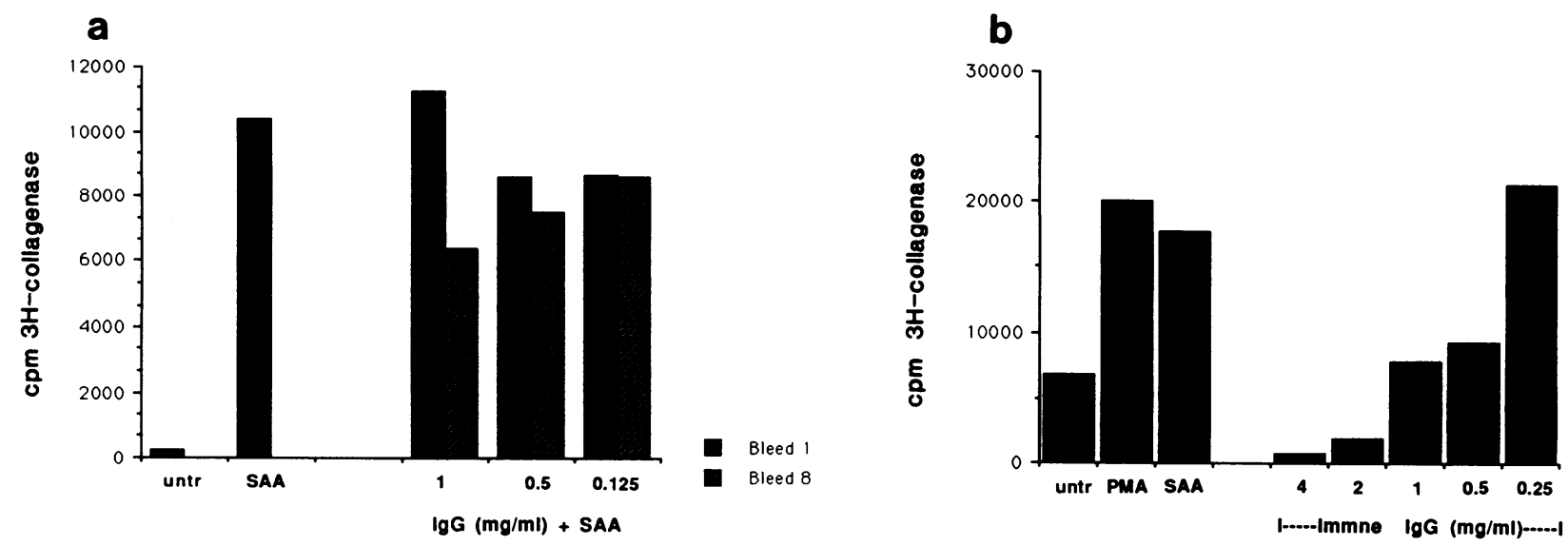

Figure 3. Neutralization of SAA induction of collagenase by anti-SAA3 IgG. IgG was prepared from nonimmune (bleed 1) or immune serum (bleed 6 or bleed 8) by standard methods, and was sterilized by filtration. To test for neutralization, the IgG was mixed with purified amyloid protein $(6 \mu \mathrm{g} / \mathrm{ml})$ and incubated at $37^{\circ} \mathrm{C}$ for $2 \mathrm{~h}$. The mixture was then centrifuged for $5^{\prime}$ at $12,000 \mathrm{~g}$ and the supernatant was added to monolayer cultures of rabbit synovial fibroblasts in leucine-free medium. ${ }^{3} \mathrm{H}$-Leucine $(25 \mu \mathrm{c} / \mathrm{ml})$ was added, the cultures were incubated for 30 $\mathrm{h}$ at $37^{\circ} \mathrm{C}$, and the amount of ${ }^{3} \mathrm{H}$-collagenase synthesized was determined by immunoprecipitation with monospecific antibody to collagenase and by $7.5 \%$ acrylamide gel and fluorography. ${ }^{3} \mathrm{H}$-Collagenase was quantitated by excising the protein bands and counting them by liquid scintillation counting. Total cellular protein was measured and results are expressed as $\mathrm{cpm} / 100 \mu \mathrm{g}$. (a) Nonimmune vs. immune IgG. Bleed 1 (nonimmune) and bleed 8 (immune). Solid bar of SAA alone is a positive control; no IgG was added. (b) Dose/response curve of immune IgG (bleed 6) in the presence of SAA.

ogy with human SAA3 is most apparent at the $\mathrm{NH}_{2}$-terminus, where there are only four mismatches out of 25 residues, compared to 12 of 25 when human SAA1 is compared to the rabbit protein (Fig. $4 \mathrm{~b}$ ). These data suggest that SAA3 is the form of SAA expressed by rabbit fibroblasts and that we have cloned this protein. We also note that the deduced sequences for residues $32-45$ is completely conserved, as has been reported for all of the AA proteins examined thus far (20) (see Discussion below).

Constitutive production of SAA and collagenase and induction by PMA and IL-1. To begin to understand the relationship between levels of SAA and collagenase synthesis, we measured the constitutive production of both proteins in cells at low passage (passage 3 or 6 ) and at higher passage (passage 16), and then we compared the ability of PMA and IL-1 to stimulate the synthesis of SAA and collagenase in these cells. A representative experiment demonstrating constitutive expression of SAA and collagenase production over a 72 -h time period is presented in Fig. 5, and shows that young (passage 3 ) cells produced higher constitutive levels of SAA and collagenase, whereas cells at passage 6 and 16 produced progressively lower levels of both proteins. Compared to passage 3 cells, passage 6 cells secreted $\sim 50 \%$ less SAA and collagenase and passage 16 cells secreted only $15-20 \%$. However, for cells at any given passage, the amount of SAA and collagenase remained fairly constant over the 72-h culture period. It is important to note that although the passage 3 cells have relatively high constitutive levels of both SAA and collagenase, collagenase is still inducible with PMA and IL-1 (see below).

We next compared the ability of cells at passage 3,6 , or 16 to synthesize either SAA or collagenase in response to treatment with either PMA or IL-1 (Fig. 6). Experiment 1 was carried out with cells from the same rabbit, whereas experiment 2 was performed with cells from different rabbits. Measuring SAA production (Fig. $6 a$ ), we found that in passage 3 cells SAA did not increase after $24 \mathrm{~h}$ of treatment with either
PMA or IL-1, perhaps because these young cells are already synthesizing high levels of SAA constitutively. Further exposure to either PMA or IL-1 for as long as $72 \mathrm{~h}$ did not change SAA levels (data not shown). When passage 6 cells were stimulated with PMA or IL-1, an increase in SAA was seen, and this increase was maintained if the cells were stimulated for $72 \mathrm{~h}$ (data not shown). In contrast, passage 16 cells had low constitutive levels which were not increased by a 24-h treatment with PMA or IL-1, and which increased hardly at all after $72 \mathrm{~h}$ in culture.

When collagenase levels were measured in these cells, both passage 3 and passage 6 cells responded well to phorbol or IL-1 (Fig. $6 \mathrm{~b}$ ), and this increase was sustained over $72 \mathrm{~h}$ in culture (data not shown). On the other hand, passage 16 cells at $24 \mathrm{~h}$ responded weakly if at all to either phorbol or IL-1 and it is only after a prolonged treatment of $72 \mathrm{~h}$ with PMA that an increase in collagenase was seen. IL-1 did not induce collagenase in the higher passage cells.

It is essential to point out that these data illustrate trends, rather than absolute values. Not every population of rabbit fibroblasts at a given passage will express the identical amount of SAA or collagenase. However, we can conclude that as passage number increases, constitutive production of both SAA and collagenase decreases, the cells become more refractory to stimulation, and only prolonged treatment with phorbol will boost collagenase levels. These results have been confirmed qualitatively with Western blots of nonradioactive culture medium tested against antibodies to SAA and collagenase (data not shown). Because similar results were seen regardless of whether the cells were derived from a single rabbit or from several rabbits, the differences observed are not due to differences among cells derived from different rabbits, but rather, are passage-dependent.

Because higher levels of SAA are associated with young cells which are already synthesizing elevated levels of collagenase and which can readily be stimulated further, we interpret 


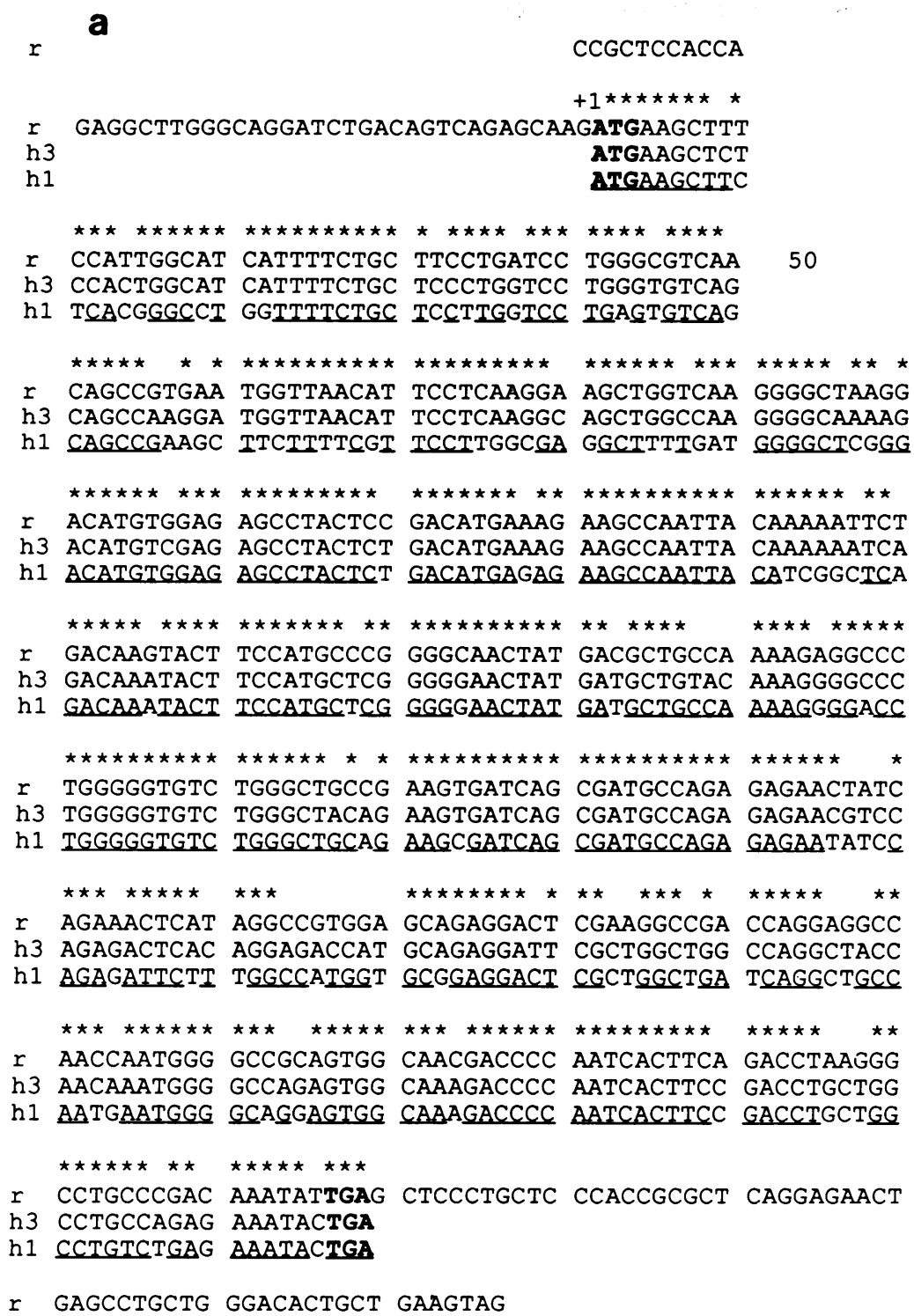

r GAGCCTGCTG GGACACTGCT GAAGTAG

200 Figure 4. Nucleic acid and protein sequence analysis of rabbit SAA protein. $\sim 10^{5}$ plaques from a cDNA library prepared in lambda gt 11 with mRNA from PMA-stimulated rabbit

250 fibroblasts were screened with a cDNA clone for human SAA2 (6). Six positive clones were purified through three rounds of plaque purification, and subcloned into the Bluescript plasmid for di-deoxysequencing with the aid of a

300 "helper phage" (Stratagene, Inc.) to produce single-stranded DNA. One clone was fulllength, and this sequence is shown and compared with human SAA1 (5) and SAA3 (9), at 350 both the nucleic acid $(a)$ and amino acid $(b)$ levels. In $a$ the ATG translation start codon and the TGA stop codon are bold-faced. Homologies between rabbit SAA3 and human SAA3 are indicated by *, whereas homologies between rabbit SAA3 and human SAA1 are underlined. In $b$ amino acid mismatches are boxed out. $r$, rabbit amyloid; $h 3$, human SAA3; $450 h l$, human SAA1. these findings to suggest that $(a)$ increased levels of SAA may represent an "activated" cell which is already making some collagenase and which is predisposed to further stimulation with IL-1 or phorbol and $(b)$ prolonged stimulation of older cells may be necessary to first "activate" these cells so that they can respond to inducers, perhaps by an SAA-independent mechanism (see Discussion below).

Time course for the appearance of SAA and collagenase. To further understand the mechanism of SAA induction of collagenase synthesis, we used cells at passage 5 to determine a time course for increases in SAA and collagenase after addition of phorbol. Because an increase in $c$-jun is associated with increased collagenase production $(21,22)$, we also measured $c$ jun mRNA. Phorbol was added to monolayers of fibroblasts in serum-free medium, and at intervals, selected cultures were terminated and analyzed for SAA, $c$-jun, and collagenase mRNAs (Fig. 7). Cells expressed some SAA mRNA constitutively at time 0 , and after addition of PMA, SAA mRNA increased by $1.5 \mathrm{~h}$. c-Jun mRNA increased by $3 \mathrm{~h}$ and was still elevated at $8.5 \mathrm{~h}$. Collagenase mRNA was first detected at $5 \mathrm{~h}$. When SAA and collagenase proteins were measured in the culture medium of these cells, SAA protein increased by $3 \mathrm{~h}$ and collagenase protein was detected at $7 \mathrm{~h}$ (Fig. 8).

In a second experiment with cells at passage 11 , we noted that neither SAA nor $c$-jun mRNAs were detected at $2 \mathrm{~h}$, but both were increased at $5 \mathrm{~h}$, followed by collagenase at $8 \mathrm{~h}$ (data not shown). Thus, as in the previous experiment (Fig. 6), there is a correlation between passage number and susceptibility to induction: the older the passage number, the longer the induction period, and this longer induction is associated with a delay in increased expression of $c$-jun. Although others have noted an increase in $c$-jun before collagenase $(21,22)$, the time frame of $c$-jun expression may vary, depending on the type of cells used, the inducer, and the experimental conditions $(21,22)$. In our experiments, the only variable was passage number, yet in both experiments, our observations agree with those who have also described an increase in $c$-jun levels before an increase in collagenase $(21,22)$. 
rabbit: arg-glu- trp-leu-thr-phe-leu-lys-glu-ala-

husMa3: glingly-trp-leu-thr-phe-leu-lysfala ala-

husal : arg-ser-phe-phe-ser phe-leufgly-glu-ala-

15

20

25

30

gly-gln-gly-ala-lys-asp-met-trp-arg-ala-tyr-ser-asp-met-lys-glu-ala-asn-tyr-lys-

gly-gln-gly-ala-lys-asp-met ser-arg-ala-tyr-ser-asp-met-lys-glu-ala-asn-tyr-lysphe-asptgly-alafarg-asp-met-trp-arg-ala-tyr-ser-asp-met $\sqrt{a r g}$ glu-ala-asn-tyr-ile-

35

40

45

50

asn
ser-asp-lys-tyr-phe-his-ala-arg-gly-asn-tyr-asp-ala-ala-lys-arg-gly-pro-gly-
ser-asp-lys-tyr-phe-his-ala-arg-gly-asn-tyr-asp-ala val-gln-arg-gly-pro-gly-
glytser-asp-lys-tyr-phe-his-ala-arg-gly-asn-tyr-asp-ala-ala-lys-arg-gly-pro-gly-

55

60

65 70

gly-val-trp-ala-ala-glu-val-ile-ser-asp-ala-arg-glu-asntyr gln tys leu-ilefgly-

gly-val-trp-alafthr glu-val-ile-ser-asp-ala-arg-glu-asn-val-gln-arg-leu-thr-glygly-val-trp-ala-ala-glu-alatile-ser-asp-ala-arg-glu-asn-iletgln-arg phe-phetgly-

$\begin{array}{llll}75 & 80 & 85 & 90\end{array}$

argfgly-ala-glu-asp-ser lys ala-asp-gln glu ala-asn-gln trp-gly-arg-ser-gly-asnasp-his ala-glu-asp-ser-leu-ala gly gln-alatthr-asn-lys-trp-gly gln ser-gly-lys-

his gly-ala-glu-asp-ser-leu-ala-asp-gln-ala-ala-asn-gluttrp-gly-arg-ser-gly-lys-

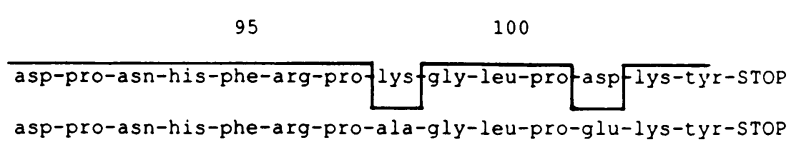

asp-pro-asn-his-phe-arg-pro-ala-gly-leu-pro-glu-lys-tyr-sTOP

Figure 4 (Continued)
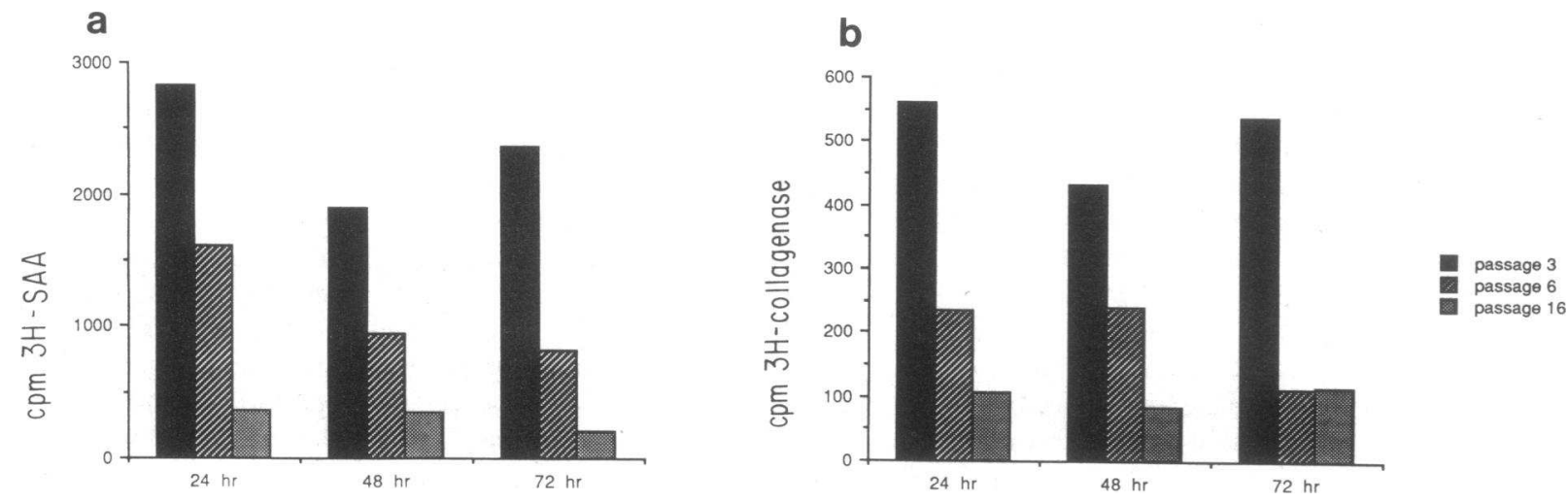

Figure 5. Constitutive production of SAA3 and collagenase by rabbit synovial fibroblasts. Rabbit synovial fibroblasts at passage 3,6 , or 16 were grown to confluence in 35-mm-diam cluster dishes in DMEM with 10\% FCS. The cells were then washed three times to remove traces of serum and placed in $2 \mathrm{ml}$ DMEM-LH. At $24 \mathrm{~h}$, the medium was replaced with leucine-free medium and the cells were pulse-labeled for $4 \mathrm{~h}$ with ${ }^{3} \mathrm{H}$-leucine. Serum-free medium was replaced on the remaining cells, and after another $24 \mathrm{~h}$ selected cultures were pulsed-labeled. The remaining cultures were again given fresh DMEM-LH; and after an additional $24 \mathrm{~h}$ (a total of $72 \mathrm{~h}$ ), these cells were also pulse-labeled. Aliquot portions of the culture medium were immunoprecipitated with monospecific antibody to rabbit SAA or collagenase, each diluted 1:100. The ${ }^{3} \mathrm{H}-\mathrm{SAA}$ and ${ }^{3} \mathrm{H}$-collagenase were visualized with a 7.5-15\% gradient polyacrylamide gel and fluorography, and were quantitated by excising the bands of protein and counting them. Total cellular protein of the monolayers was determined, and the data are expressed as cpm/100 $\mu \mathrm{g}$. 

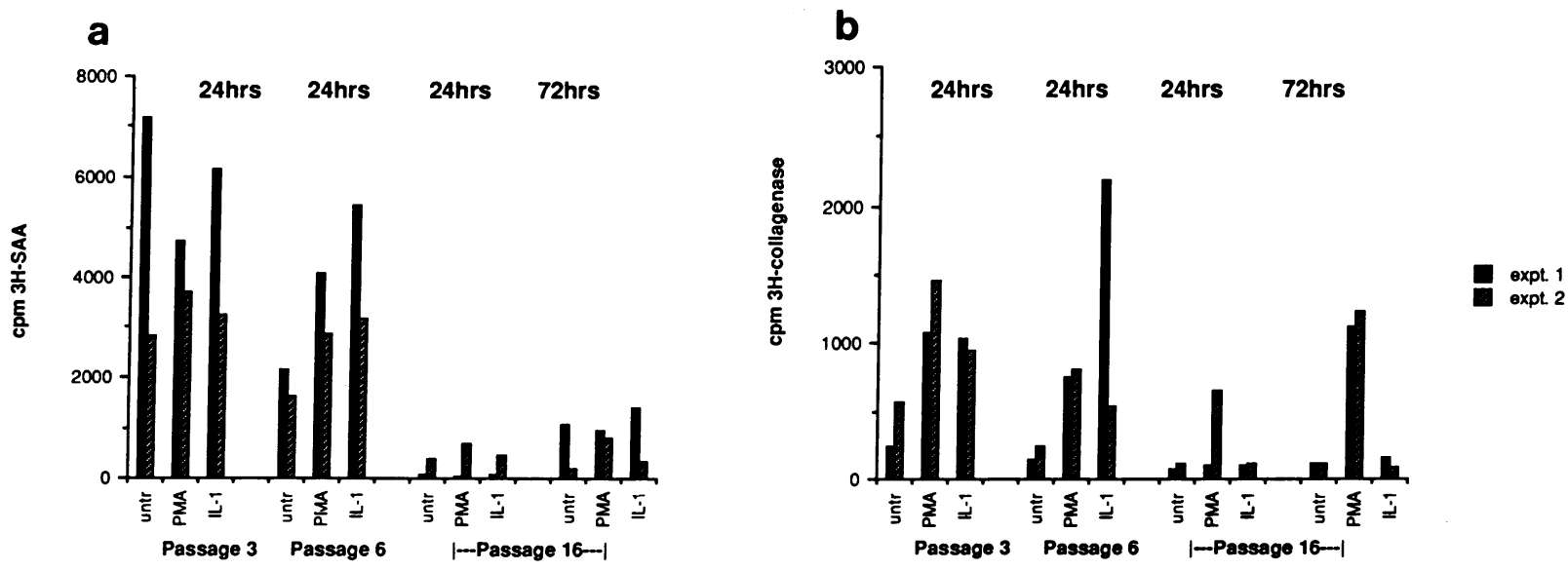

Figure 6. Induction of SAA and collagenase by PMA and IL-1. This experiment was carried out with the same rabbit synovial fibroblasts described in Fig. 5. At the start of the experiment, when selected cultures were washed and placed in $2 \mathrm{ml}$ DMEM-LH, other cultures were treated with PMA $10^{-8} \mathrm{M}$ or Il-1 $(100 \mathrm{U} / \mathrm{ml})$. At $24 \mathrm{~h}$, the medium was replaced with leucine-free medium and the cells were pulse-labeled for $4 \mathrm{~h}$ with ${ }^{3} \mathrm{H}$-leucine. Serum-free medium, with or without PMA or IL-1, was replaced in the remaining cultures, and after another $24 \mathrm{~h}$ selected cultures were pulse-labeled. The remaining cultures were again given fresh DMEM-LH and PMA or IL-1, and after an additional $24 \mathrm{~h}$ (a total of $72 \mathrm{~h}$ ), these cells were also pulsed. Aliquot portions of the culture medium were immunoprecipitated with monospecific antibody to rabbit SAA or collagenase each diluted 1:100. The ${ }^{3} \mathrm{H}$-SAA and ${ }^{3} \mathrm{H}$-collagenase were visualized with $7.5-15 \%$ gradient polyacrylamide gel and fluorography, and were quantitated by excising the bands of protein and counting them. Total cellular protein of the monolayers was determined, and the results are expressed as $\mathrm{cpm} / 100 \mu \mathrm{g}$. Experiment 1 was carried out with cells from a single rabbit, whereas experiment 2 was performed with cells from different rabbits.

\section{Discussion}

In this paper, we confirm our previous observations that SAA is produced by rabbit synovial fibroblasts and that this protein acts in an autocrine fashion to increase collagenase synthesis in these same cells. We also demonstrate that treatment with PMA or IL-1 increases SAA and that an immune IgG generated against this SAA protein neutralizes its collagenase inducing activity. Further, by sequencing a full-length cDNA for this protein, we have identified it as a rabbit form of SAA3.

As others have pointed out (20), the middle portion (residues 33-63) of the SAA proteins is widely conserved, and our rabbit protein is no exception. The amino terminus of the molecule shows more diversity and this has allowed us to compare our rabbit SAA protein to other SAA proteins. The homology between the first 25 residues of our rabbit protein and human SAA3 is striking (Fig. 4 b). We and others (9) have noted conservation of 21 of the first 25 residues, or $84 \%$. In contrast, sequence comparison of these 25 residues with human SAA1 $(5,9)$ reveals conservation of 15 of the first 25 amino acids, or only $\sim 60 \%$.

This type of sequence analysis has been helpful in identifying which form of SAA is expressed extrahepatically. Expression of SAA mRNAs has been described in tissues of animals injected with LPS or turpentine. These include lung, heart, spleen, intestines, and kidney in mice (23), and ileum, lung, and large intestine in rats (24), as well as numerous hamster tissues (19). In both the hamster and rat, the SAA3 mRNA is found only in extrahepatic tissues, leading the authors to conclude that SAA3 may be expressed abundantly at local nonhepatic sites of inflammation and tissue injury $(19,23,24)$. Our observations extend these findings by demonstrating that cultured fibroblasts of nonhepatic origin express increased amounts of SAA3 in response to two additional inflammatory mediators, PMA and IL-1. Although we cannot be certain that the rabbit SAA we have cloned is the equivalent of the SAA3 described for the rat and hamster, the evidence is suggestive. Amino acid sequence comparison of the predicted rabbit and hamster proteins reveals considerable homology between the rabbit and hamster (19) proteins: 18 of the first $25 \mathrm{NH}_{2}$-terminal residues (or $72 \%$ ) are conserved.

Our data also demonstrate a temporal relationship between the increase in SAA levels and the rise in $c$-jun mRNA which is associated with collagenase induction $(21,22)$. This temporal relationship, coupled with the ability of immune IgG to SAA to neutralize the collagenase-inducing ability of this protein, indicate a causal role for SAA3 in a pathway leading to collagenase induction. These observations allow us to hypothesize a model in which SAA triggers an intracellular pathway that leads to an increase in $c$-jun and, eventually, to an increase in collagenase mRNA. Consistent with this model is the fact that induction of collagenase requires an increase in collagenase gene transcription $(21,22,25-31)$ mediated, at least in part via an AP-1 element located in the promoter region of this gene $(21,22$, 26-28, 31).

Presently, we do not understand the signal/transduction pathway by which SAA induces collagenase. However, it is intriguing to speculate that a receptor for SAA may be involved. The complete conservation of residues $33-45$ for the SAA proteins has led to the suggestion that this portion of the molecule might be involved in binding high-density lipoprotein complexes or cellular receptors (20). Although we do not yet know if there are cellular receptors on fibroblasts for SAA protein, we speculate that differences in the levels of cellular receptors might contribute, at least in part, to differences in the responsiveness of fibroblasts to stimuli such as IL-1 and PMA.

Compared to older cells (passage 16), we noted that young cells (passage 3) had higher constitutive levels of SAA and re- 


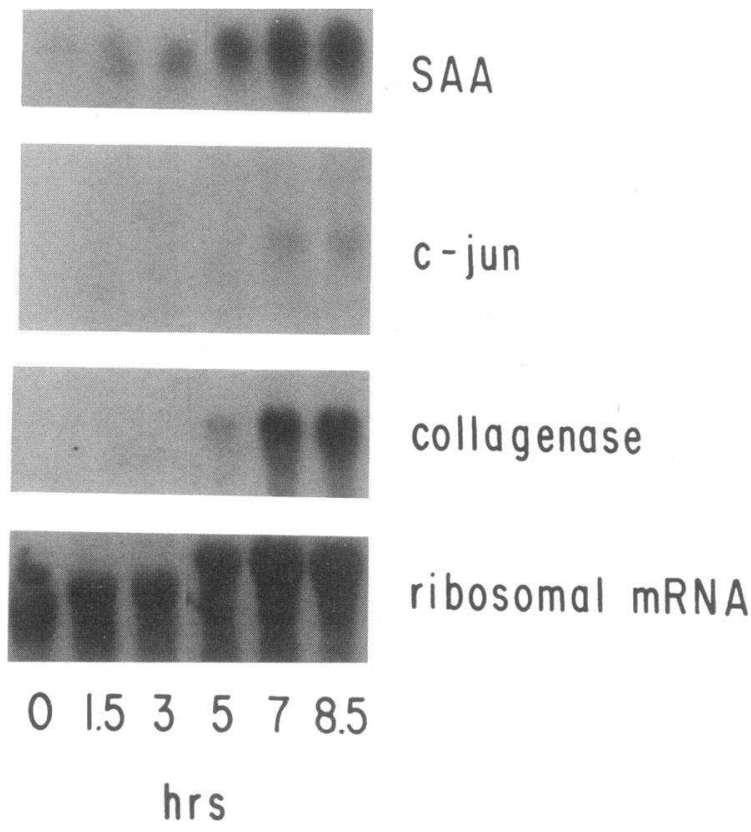

Figure 7. Time course for induction of SAA, $c$-jun and collagenase mRNAs. Rabbit synovial fibroblasts were grown to confluence in 150-mm-diam culture dishes, washed three times in HBSS to remove traces of serum and then placed in DMEM-LH and PMA $\left(10^{-8} \mathrm{M}\right)$. At selected times, RNA was harvested and analyzed by Northern blot analysis by hybridization with alpha ${ }^{32} \mathrm{P}$-labeled cDNA probes for rabbit SAA and collagenase and human $c$-jun. Ribosomal RNA, measured with an alpha ${ }^{32} \mathrm{P}$-labeled cDNA probe for mouse ribosomal gene, was used as a "housekeeping" gene to control for variations in loading. mRNAs were detected by autoradiography; SAAmRNA: $6 \mathrm{~h}$ exposure; $c$-jun, collagenase, and ribosomal mRNAs: 18-h exposure.

sponded more quickly to produce collagenase when treated with PMA or IL-1. This observation suggests that elevated levels of SAA, such as those seen in younger passage cells, may be a marker for fibroblasts that can readily be stimulated to synthesize collagenase, either by an autocrine mechanism, directly, or by the addition of exogenous stimuli, such as PMA and IL-1. The cells of older passage required prolonged exposure to inducing agents to achieve collagenase levels equal to those of younger cells, perhaps because these older cells must first be "activated" before collagenase can be induced. However, because these older passage cells produced relatively low levels of SAA even with prolonged stimulation by PMA or IL-1, it is also possible that collagenase induction may occur through an SAA-independent pathway. At the transcriptional level, both fos-dependent (28-30) and fos-independent (30) pathways for metalloproteinase induction have been reported, and it is possible that SAA-dependent and independent pathways may represent a cellular counterpart of the pathways leading to induction of metalloproteinase synthesis.

It is significant that two inflammatory stimuli, phorbol esters and IL-1, can induce SAA. These two compounds have long been known to induce collagenase, a metalloproteinase that is overexpressed in conjunction with the inflammation seen in rheumatoid arthritis $(3,11)$. Conceivably, mediators such as IL-1 could stimulate SAA3 expression in rheumatoid synovium which could, in turn, induce collagenase and enhance the degradative potential of this tissue. However, we
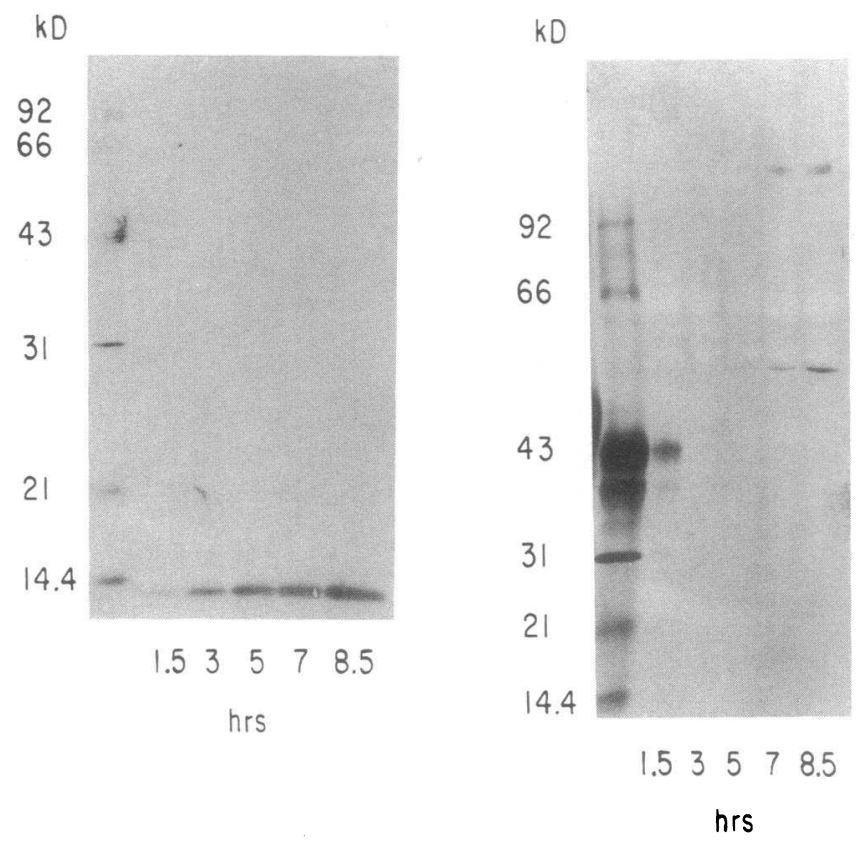

Figure 8. Time course for appearance of SAA and collagenase proteins. Serum-free culture medium was harvested from the cells described in Fig. 8 and SAA and collagenase protein were detected by Western blot analysis. Culture medium proteins were separated with a 7.5 to $15 \%$ gradient polyacrylamide gel, blotted onto Immobilon. Blots were reacted with polyclonal antisera to SAA and collagenase diluted 1:30,000 and 1:10,000, respectively, and color was developed as described in Methods. (a) SAA protein. (b) Collagenase protein.

have not yet identified this protein in human tissue, perhaps because, as has been suggested, the mRNA has a short half-life and/or because this protein is readily degraded $(9,32)$. Alternatively, it is possible that SAA is not expressed in human rheumatoid synovial cells, and that $\beta_{2}$ microglobulin plays a role. Indeed, $\beta_{2}$ microglobulin is also an autocrine inducer of collagenase $(10)$ and its expression is increased by IL-1 treatment of human synovial tissue (22).

In conclusion, our data and those of other investigators suggest that SAA3 is a distinct SAA gene product that is expressed at tissue-specific sites of local inflammation and injury in response to stimuli such as IL-1 and phorbol esters. One function of this locally produced SAA is the induction of metalloproteinases, potent modulators of the extracellular matrix. Elevated production of SAA3 by fibroblasts may be a marker for cells that are already synthesizing elevated levels of metalloproteinases constitutively and/or for cells that can readily be stimulated to synthesize these enzymes. As such, SAA3 may play a direct role mediating inflammatory responses.

\section{Acknowledgments}

We thank Dr. David Auble and Ms. Anne Delany (Hanover, NH) for helpful suggestions, and we gratefully acknowledge Drs. Barbara Kluve-Beckerman and Merrill Benson (Indianapolis, IN) for critical reading of the manuscript.

Supported by grants from the Council for Tobacco Research and the RGK Foundation. 


\section{References}

1. Kushner, I. 1982. The phenomenon of the acute phase response. Ann. NY Acad. Sci. 389:39-48.

2. Kushner, I., M. Ganapathi, and D. Schultz. 1989. The acute phase response is mediated by heterogeneous mechanisms. Ann. NY Acad. Sci. 557:19-30.

3. Kelley, W. N., E. D. Harris, S. Ruddy, and C. B. Sledge, editor. 1989. Textbook of Rheumatology. W. B. Saunders Co., Philadelphia.

4. Lowell, C. A., D. A. Potters, R. S. Stearman, and J. F. Morrow. 1986 Structure of the murine serum amyloid A gene family. J. Biol. Chem. 261:84428452.

5. Sipe, J. D., H. R. Colten, G. Goldberger, M. D. Edge, B. F. Tack, A. S Cohen, and A. S. Whitehead. 1985. Human serum amyloid A (SAA): biosynthesis and postsynthetic processing of preSAA and structural variants defined by complementary DNA. Biochemistry. 24:2931-2936.

6. Kluve-Beckerman, B., G. L. Long, and M. D. Benson. 1986. DNA sequence evidence for polymorphic forms of human serum amyloid A (SAA). Biochem. Genet. 24:795-803.

7. Woo, P., J. Sipe, C. A. Dinarello, and H. R. Colten. 1987. Structure of a human serum amyloid $A$ gene and modulation of its expression in transfected $\mathrm{L}$ cells. J. Biol. Chem. 262:15790-15795.

8. Parmelee, D. C., K. Titani, L. H. Ericcson, N. Eriksen, E. P. Benditt, and K. A. Walsh. 1982. Amino acid sequence of amyloid-related apoprotein (apoSAA) from human high density lipoprotein. Biochemistry. 21:3298-3303.

9. Sack, G. H., and C. C. Talbot, Jr. 1989. The human serum amyloid A (SAA)-encoding gene GSAA1: nucleotide sequence and possible autocrine-collagenase-inducer function. Gene (Amst.). 84:509-515.

10. Brinckerhoff, C. E., T. I. Mitchell, M. J. Karmilowicz, B. Kluve-Beckerman, and M. D. Benson. 1989. Autocrine induction of collagenase by serum amyloid A-like and $\beta_{2}$-microglobulin-like proteins. Science (Wash. DC). 243:655-657.

11. Brinckerhoff, C. E., and M. E. Fini. 1989. Molecular cloning of collagenase and activator/stromelysin: members of a coordinately regulated gene family of metalloproteinases important in the modulation of connective tissue metabolism. In Collagen. Vol. IV. Molecular Biology. B. J. Olsen and M. E. Nimni, editors. CRC Press, Inc., Boca Raton, FL. 65-84.

12. Brinckerhoff, C. E., and T. I. Mitchell. 1988. Autocrine control of collagenase synthesis. J. Cell. Physiol. 136:72-80.

13. Fini, M. E., M. J. Karmilowicz, P. L. Ruby, A. M. Beeman, K. A. Borges, and C. E. Brinckerhoff. 1987. Cloning of a complementary DNA for rabbit proactivator. A metalloproteinase that activates synovial cell collagenase, shares homology with stromelysin and transin, and is coordinately regulated with collagenase. Arth. Rheum. 30:1255-1264.

14. Feinberg, A., and B. Vogelstein. 1983. A technique for radiolabeling restriction fragments to high specific activity. Anal. Biochem. 132:6-13. (Addendum, 137:266-267.)

15. Sanger, F., S. Nicklen, and A. R. Coulsen. 1977. DNA sequencing with chain-terminating inhibitors. Proc. Natl. Acad. Sci. USA. 74:5463-5467.

16. Chirgwin, J. M., A. E. Przybyla, R. J. MacDonald, and W. J. Ruther. 1979. Isolation of biologically active ribonucleic acid from sources enriched in ribonuclease. Biochemistry. 18:5294-5299.
17. Gross, R. H., L. S. Sheldon, C. F. Fletcher, and C. E. Brinckerhoff. 1984 Isolation of a collagenase cDNA clone and measurement of changing collagenase mRNA levels during induction in rabbit synovial fibroblasts. Proc. Natl. Acad. Sci. USA. 81:1981-1985.

18. Tiemeier, O. C., S. M. Tiglhman, and P. Leder. 1977. Purification and cloning of a mouse ribosomal gene fragment in coliphage lambda. Gene (Amst.) 2:173-191.

19. Webb, C. F., P. W. Tucker, and S. B. Dowton. 1989. Expression and sequence analyses of serum amyloid $\mathrm{A}$ in the syrian hamster. Biochemistry. 28:4785-4790.

20. Kluve-Beckerman, B., F. E. Dwulet, S. P. DiBartola, and M. D. Benson 1989. Primary structures of dog and cat amyloid A proteins: comparison to human AA. Comp. Biochem. Physiol. 94B:175-183.

21. Brenner, D. A., M. O'Hara, P. Angel, M. Chojkier, and M. Karin. 1989. Prolonged activation of jun and collagenase genes by tumor necrosis factor alpha. Nature (Lond.). 337:661-663.

22. Conca, W., P. B. Kaplan, and S. M. Krane. 1989. Increases in levels of procollagenase mRNA in cultured fibroblasts induced by human recombinant interleukin $1 \beta$ or serum follow c-jun expression and are dependent on new protein synthesis. J. Clin. Invest. 83:1753-1757.

23. Ramadori, G., J. D. Sipe, and H. R. Colten. 1985. Expression and regulation of the murine serum amyloid A (SAA) gene in extrahepatic sites. J. Immunol. 135:3645-3647.

24. Meek, R. L., and E. P. Benditt. 1989. Rat tissues express serum amyloid A protein-related mRNAs. Proc. Natl. Acad. Sci. USA. 86:1890-1894.

25. Brinckerhoff, C. E., I. M. Plucinska, L. A. Sheldon, and G. T. O’Connor 1986. Half-life of synovial cell collagenase mRNA is modulated by phorbol myristate acetate but not by all-trans-retinoic acid or dexamethasone. Biochemistry. 25:6378-6384.

26. Angel, P., I. Baumann, B. Stein, H. Delius, H. J. Rahmsdorf, and P. Herrlich. 1987. 12-O-Tetradecanoyl-phorbol-13-acetate induction of the human collagenase gene is mediated by an inducible enhancer element located in the 5'-flanking region. Mol. Cell. Biol. 7:2256-2266.

27. Angel, P., M. Imagawa, R. Chiu, B. Stein, R. J. Imbra, H. J. Ramsdorf, C. Jonat, P. Herrlich, and M. Karin. 1987. Phorbol ester-inducible genes contain a common cis element recognized by a TPA-modulated trans-acting factor. Cell. 49:729-739.

28. Chiu, R., W. J. Boyle, J. Meek, T. Smeal, T. Hunter, and M. Karin. 1988. The c-fos protein interacts with c-jun/AP-1 to stimulate transcription of AP-1 responsive genes. Cell. 54:541-552.

29. Schonthall, A., P. Herrich, H. J. Rahmsdorf, and H. Ponta. 1988. Requirement for fos gene expression in the transcriptional activation of collagenase by other oncogenes and phorbol esters. Cell. 54:325-334.

30. Kerr, L. D., J. T. Holt, and L. M. Matrisian. 1989. Growth factors require transin gene expression by c-fos-dependent and c-fos-independent pathways. Science (Wash. DC). 242:1424-1427.

31. Auble, D. T., and C. E. Brinckerhoff. 1991. The AP-1 sequence is necessary but not sufficient for phorbol induction of collagenase in fibroblasts. Biochemis try. In press.

32. Lowell, C. A., R. S. Stearman, and J. I. Morrow. 1986. Transcriptional regulation of serum amyloid A gene expression. J. Biol. Chem. 261:8453-8461. 